\title{
Influence of the coating process parameters on the quality of PUR/PVP hydrogel coatings for PVC medical devices
}

\author{
Anna E. Paradowska*, Katarzyna A. Kaźmierska, Tomasz Ciach \\ Warsaw University of Technology, The Faculty of Chemical and Process Engineering, ul. Warynskiego 1, \\ 00-645 Warszawa, Poland, e-mail: T.Ciach@ichip.pw.edu.pl \\ * Corresponding Author: e-mail: aparadowska@wum.edu.pl, current affiliation: Medical University of Warsaw, Depart- \\ ment of General and Nutritional Biochemistry, ul. Banacha 1, 02-097 Warszawa, Poland
}

\begin{abstract}
To decrease friction factor and enhance the biocompatibility of medical devices manufactured from poly(vinyl chloride), PVC, the surface modification with wear resistant polyurethane/polyvinylpyrrolidone (PUR/PVP) hydrogel coating can be applied. In the present work substrates were dip-coated with PVP and PUR solutions and thermally cured. The variable process parameters were: solvent system; concentration of polymers $(1$, 2 or $3 \% \mathrm{w} / \mathrm{v})$; coating baths temperature $\left(22,38\right.$ and $\left.55^{\circ} \mathrm{C}\right)$; drying temperature $\left(32,50\right.$ and $\left.67^{\circ} \mathrm{C}\right)$; length of break between process steps $(5,30$ and $90 \mathrm{~s}$ ); and solutions storage time (up to $72 \mathrm{hrs}$ ). The quality of coatings was determined by friction coefficients against porcine aorta, weights of the deposited layer and the swelling capacity. The solvent system and polymers concentration were crucial factors. The increased temperature of coating solutions caused increased deposition but decreased durability. The most lubricious samples were dried in $50^{\circ} \mathrm{C}$. Coatings from the solutions prepared $24 \mathrm{~h}$ prior to use had better properties than those from fresh solutions.
\end{abstract}

Keywords: Hydrogel coatings, dip-coating, poly(vinyl chloride), polyvinylpyrrolidone.

\section{INTRODUCTION}

Hydrogels are a special class of hydrophilic polymers that imbibe a considerable amount of water or biological fluids while maintaining their overall shape ${ }^{1}$. Their threedimensional networks, composed of homopolymers or copolymers, remain insoluble due to the presence of chemical or physical crosslinks ${ }^{2}$. Therefore hydrogels exhibit both liquid-like and solid like properties. The first results from the fact that the major constituent is water, and the latter is provided by the network structure of the polymer chains and their physical integrity ${ }^{3}$. Due to the relatively high water content as well as soft and rubbery consistency, hydrogels resemble natural living tissue which, in addition to an inert or positive interaction with the host tissue, contributes to their biocompatibility ${ }^{4,5}$.

The development of synthetic hydrogels dates back to 1960s, when Wichterle and Lim suggested use of hydrophilic networks of poly(2-hydroxyethyl methacrylate) (pHEMA) to form contact lenses ${ }^{6}$. The subsequent achievement in this field was the utilization of calcium alginate as a drug matrix ${ }^{7}$. Since then, hydrogels have gained in importance in the biomedical and pharmaceutical applications, which can be classified into three different categories. Namely: coatings on the commonly used devices such as catheters or vascular stents, homogenous materials (e.g. contact lenses, wound dressing, artificial corneas) and drug delivery systems ${ }^{3}$.

The usage of hydrogels in their pure state, as "homogeneous" materials, is limited due to low mechanical strength and flimsiness of the highly hydrated polymer networks. Surface modification, however, enables the integration of the good mechanical properties of base polymers such as polyurethane (PUR) or poly(vinyl chloride) (PVC) with benefits provided by biocompatibile, slippery and humid hydrogels. By application of hydrophilic coatings on medical devices many problems such as inflamatory response, sensitisation or mechanical irritation to surround- ing tissue can be avoided or minimised. Several studies have shown that surface modification of urinary catheters with hydrophilic polymers is a promising approach in the reduction of both encrustation and bacterial adherence ${ }^{8-10}$.

Many different techniques of coating have been developed. One of the most simple and comfortable, especially on a laboratory scale, is dip-coating that involves a vessel filled with polymer solution into which the device is immersed and then withdrawn ${ }^{11}$.

In medicine PVC represents more than $25 \%$ of applied plastics. According to the rule: "optimal effect at minimum cost", as the operation scales up, financial expenses, associated with the usage of raw material and energy, should be as low as possible. Particularly in the case of coatings for the cheapest devices. As there are several factors determining the dip-coating method efficiency ${ }^{11}$, the aim of this study was to investigate the influence of the hydrogel formation process parameters on the quality and stability of the obtained coatings.

\section{EXPERIMENTAL}

\section{Materials}

As the substrates for surface modification were used: Nelaton type $\mathrm{CH} 14$ urethral catheters, kindly provided by the manufacturer, Galmed (Bydgoszcz, Poland), and tubes made of plasticized PVC, purchased from a local distributor $(9.7 \mathrm{~mm}$ and $6.9 \mathrm{~mm}$ of outer and inner diameter, respectively). Coating polymers and additives: polyvinylpyrrolidone K90 (MW ca. $1300 \mathrm{kDa}$ ) was purchased from Sigma Aldrich; the term polyurethane (PUR) refers to ESTANE 5715P; urea and anhydrous glycerol were supplied by Chempur. All the used organic solvents, namely: tetrahydrofuran (THF), propan-2-ol (iPA), cyclohexanone, dichloromethane, ethyl acetate, n-butyl acetate (all purchased from Chempur) and 2-butanone (MEK) (purchased from $\mathrm{POCH}$ ) were of analytical grade. 
Table 1. Tested solvent systems

\begin{tabular}{|c|c|c|c|c|}
\hline system & Step 1 (PUR) & & Step 2 (PVP) & \\
\hline A & THF & $100 \%$ & $\begin{array}{l}\text { iPA } \\
\text { THF }\end{array}$ & $\begin{array}{l}25 \% \\
75 \%\end{array}$ \\
\hline B & MEK & $100 \%$ & $\begin{array}{l}\text { iPA } \\
\text { MEK }\end{array}$ & $\begin{array}{l}25 \% \\
75 \%\end{array}$ \\
\hline C & $\begin{array}{l}\text { MEK } \\
\text { ethyl acetate }\end{array}$ & $\begin{array}{l}50 \% \\
50 \% \\
\end{array}$ & $\begin{array}{l}\text { iPA } \\
\text { MEK }\end{array}$ & $\begin{array}{l}25 \% \\
75 \% \\
\end{array}$ \\
\hline D & $\begin{array}{l}\text { ethyl acetate } \\
\text { dichloromethane }\end{array}$ & $\begin{array}{l}50 \% \\
50 \% \\
\end{array}$ & $\begin{array}{l}\text { iPA } \\
\text { ethyl acetate }\end{array}$ & $\begin{array}{l}40 \% \\
60 \% \\
\end{array}$ \\
\hline E & MEK dichloromethane & $\begin{array}{l}50 \% \\
50 \% \\
\end{array}$ & $\begin{array}{l}\text { iPA } \\
\text { MEK }\end{array}$ & $\begin{array}{l}40 \% \\
60 \% \\
\end{array}$ \\
\hline $\mathrm{F}$ & $\begin{array}{l}\text { n-butyl acetate } \\
\text { dichloromethane }\end{array}$ & $\begin{array}{l}50 \% \\
50 \% \\
\end{array}$ & $\begin{array}{l}\text { iPA } \\
\text { n-butyl acetate }\end{array}$ & $\begin{array}{l}40 \% \\
60 \%\end{array}$ \\
\hline G & $\begin{array}{l}\text { MEK } \\
\text { ethyl acetate } \\
\text { cyclohexanone }\end{array}$ & $\begin{array}{l}25 \% \\
25 \% \\
50 \%\end{array}$ & $\begin{array}{l}\text { iPA } \\
\text { cyclohexanone } \\
\text { ethyl acetate }\end{array}$ & $\begin{array}{l}50 \% \\
30 \% \\
20 \%\end{array}$ \\
\hline
\end{tabular}

All the chemicals were used as received, without further purification.

\section{Coating process}

In this study the coating system previously proposed by Micklus ${ }^{12}$ and modified by omitting the addition of diisocyanates was applied ${ }^{13,14}$. The process consists of two steps: in the first the device made of plasticized PVC is immersed in polyurethane (PUR) solution, air dried, and then dipped into polyvinylpyrrolidone (PVP) solution (typically, if not indicated, 1\% PUR and 3\% PVP, $\mathrm{v} / \mathrm{w}$ ). In each step immersion takes about 30 seconds and is followed by about 2 minutes of hot air drying. The combination of the effect of organic solvents and nonsolvents and an elevated drying temperature results in the formation of PUR/PVP interpolymer layer on the PVC surface.

Thin film samples were prepared by pouring the defined volumes of both polymer solutions into tray, according to the same procedure, the only difference was the lack of PVC backbone.

\section{Variable process parameters}

A choice of the solvent system was considered at the very beginning, as the factor responsible for the proper adherence of the newly obtained coating to the backbone. The tested solvent systems are summarized in Table 1. Compositions giving the highest quality coatings (resistant to wear and exhibiting low wet friction coefficient) were used in subsequent studies.

To determine the optimal concentrations of coating solutions of both polymers (PUR and PVP), samples containing 1,2 and $3 \%(\mathrm{w} / \mathrm{v})$ in all possible combinations were prepared.

In further investigation application of coating was carried out just after polymer solutions had been prepared $(0 \mathrm{~h})$ and after longer storage time (24 and $72 \mathrm{~h})$. Care has been taken to prevent the coating formulation from the loss of solvents.

To verify if the drying temperature significantly affects coating stability, tubes after the modification procedure were incubated for 5 minutes at 3 different tempertaures: 32,50 and $68^{\circ} \mathrm{C}$.

The composition that forms the most lubricious coating was utilized to investigate the influence of solution temperature (rt versus heated up to 40 and $55^{\circ} \mathrm{C}$ before the device immersion) and the length of break between the first and the second process step (5, 20,30 and $90 \mathrm{~s}$ ) on the quality of the obtained hydrogel layer. All experiments verifying the influence of viable process parameters were conducted at least in triplicate.

\section{Stability of hydrogel coatings}

The modified samples were submerged in water for 24 $\mathrm{h}$, then dried and weighed. The stability of the deposited polymer layer was calculated from the following equation:

Stability $=\frac{W_{d}}{W_{0}} \cdot 100 \%$,

where $W_{d}$ is a weight of a dry gel after $24 \mathrm{~h}$ immersion in water and $W_{o}$ is an initial weight of dry gel.

\section{Tribomertric device}

The surface properties of PVP/PUR-coated substrates in hydrated state were examined using the method described in ${ }^{13}$. The static and kinetic friction coefficients, measured in contact with porcine aorta, were compared with those determined for uncoated PVC tubes or catheters (with the same method).

\section{Swelling measurements}

The swelling behavior of the PVP/PUR interpolymers was evaluated using two techniques. In the first (method I), according to the blot and weight method, the samples were immersed in distilled water at ambient temperature and weighted at various time intervals, after the water on the surface of the swollen gels was removed with filter paper. The swelling weight ratio was defined as:

$\mathrm{S}=\frac{W_{t}}{W_{d}}$,

where $W_{t}$ and $W_{d}$ are the weight of the gel at predetermined time and the weight of dried gel, respectively ${ }^{15}$. $S$ increases with time until a constant value, which represents the equilibrum state of swelling $S_{e q}$ :

Seq $=\frac{W_{s w}}{W_{d}}$,

where $W_{s w}$ is a weight of the fully swollen gel.

The obtained $W_{s w}$ enables determination of $\mathrm{C}_{\mathrm{w}}$ - equilibrium water content relative to the swollen gel - one of 
more basic properties used to characterise hydrogels and their capacity to imbibe water.

$C_{w}=\frac{\left(W_{s w}-W_{d}\right)}{W_{s w}} \cdot 100 \%$

The second method (method II) involves immersion of a sample in water for $24 \mathrm{~h}$ to reach the equilibrum state of swelling and its subsequent continuous weighting over time as water evaporates. The excess water from the sample surface evaporates relatively faster than that from the hydrogel bulk. This change in evaporation rates can be easily noticed when presented in the graphic form. The extrapolation to time zero allows determining the approximate weight of the completely swollen hydrogel $\left(\mathrm{W}_{\mathrm{sw}}\right)^{\mathbf{1 1}}$.

\section{FTIR-ATR measurements}

IR spectra of interpolymer PVP/PUR solid sample (thin films), hydrogel layers and unmodified surface devices were obtained with Fourier Transform Infrared Attenuated Total Reflectance (FTIR-ATR) spectroscopy (Nicolet 6700 with Smart Orbit diamond ATR accessory, Thermo Scientific). For each sample, 32 scans at a $2-\mathrm{cm}^{-1}$ resolution were collected.

\section{RESULTS AND DISCUSSION}

One of the most important features of a medical catheter is the allowance for easy insertion and removal after having performed its required function. Therefore, the main aim of the modification process was to make the surface more hydrophilic and to minimize the frictional forces between hydrated material surface and the host tissue. In addition, the device should exhibit the described above properties in a stable manner, as it is crucial to the success of the given operation.

In the present study we assessed the lubricity of PVP/ PUR-coated tubes and catheters, whose hydrogel layers were obtained by gellation from different polymer solutions and under various conditions. In all the cases the mass of polymers that binds with the surface after coating application and which remains after dipping the modified device in water for $24 \mathrm{~h}$ was determined. For the durable polymer layers, that seemed to be lubricious, the friction coefficients were measured. Among all the tested solvent systems only that containing n-butyl acetate could not be used, as it did not dissolve both PUR and PVP. The rest of the prepared polymer solutions were clear and formed slippery coatings. The change in the physical properties of tube and catheter surfaces after hydrogel layer application was confirmed by the tribological tests. Conducting them we paid more attention to the kinetic friction coefficient as this, being inversely related to the lubricity, had the significant influence on trauma at the device-tissue interface during the insertion. In general, all substrates with hydrophilic coatings showed the reduced friction coefficient, measured in contact with porcine aorta, in comparison with unmodified devices. Further examination revealed that hydrogel layers made of only three of the tested solvent systems (namely: A, E and G) were quite stable but not to the equal degree. Figure 1 shows the average mass of polymers that binds with surface before and after washing out.

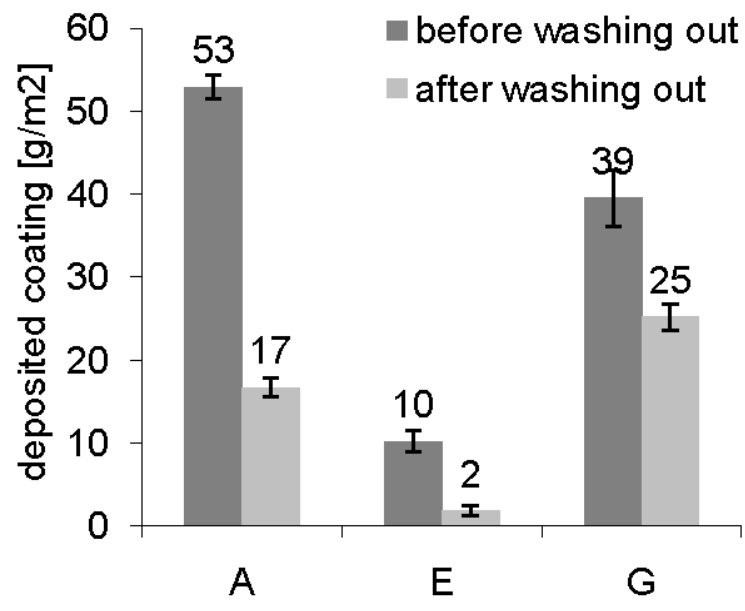

Figure 1. The weight of the deposited coating from different solvent systems (A, E, G) per square meter of the substrate's surface

Coatings obtained from systems A and G turned out to be the most lubricious (the lowest values of the reduced friction coefficient, as presented in Figure 2). The first seemed to form smoother surface, while the coating prepared from system $\mathrm{G}$ was considerably rougher but also twice as durable. These observations concerned both catheters and tubes, thus do not depend on the properties of the PVC backbone.

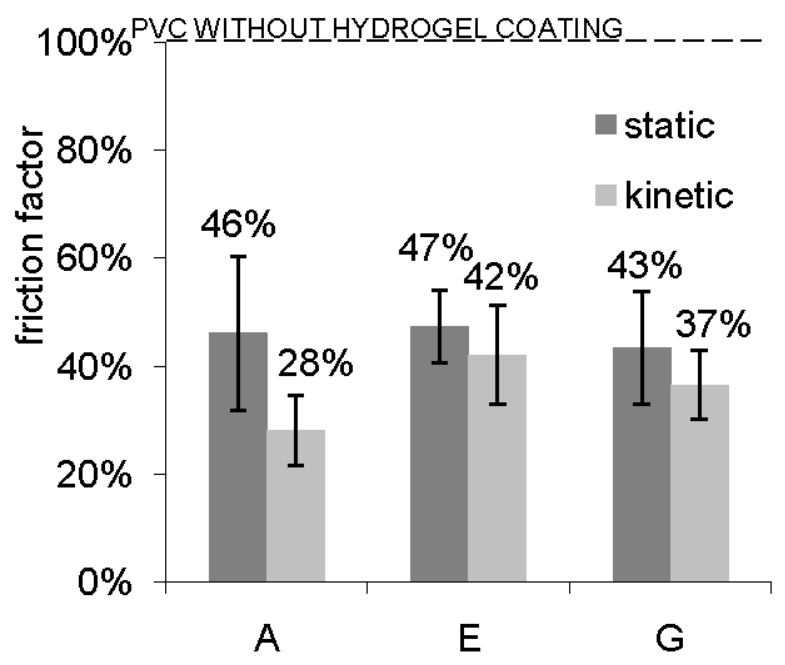

Figure 2. Relative coefficient of wet friction of PVC surfaces coated with hydrogel from different solvent systems (A, E, G); friction factor of the unmodified $\mathrm{PVC}$ is equal $100 \%$; the lower the value, the more lubricious effect

According to the tribological test results, the hydrogel layer formed from system A proved to be the most lubricious; therefore this solvent system was used to determine the optimal PUR and PVP concentrations.

The deposited coatings (before and after washing out), hydrogel layers stabilities and reduced static and kinetic friction factors are presented in Figures 3 and 4.

The highest reduction of kinetic friction coefficient was achieved when 1\% PUR and 3\% PVP had been applied (Fig. 4.b). It is worth noticing that this coating, when tested manually, possessed the smoothest texture. Using 2 and $3 \%(\mathrm{w} / \mathrm{v})$ PUR concentration resulted in poorer per- 

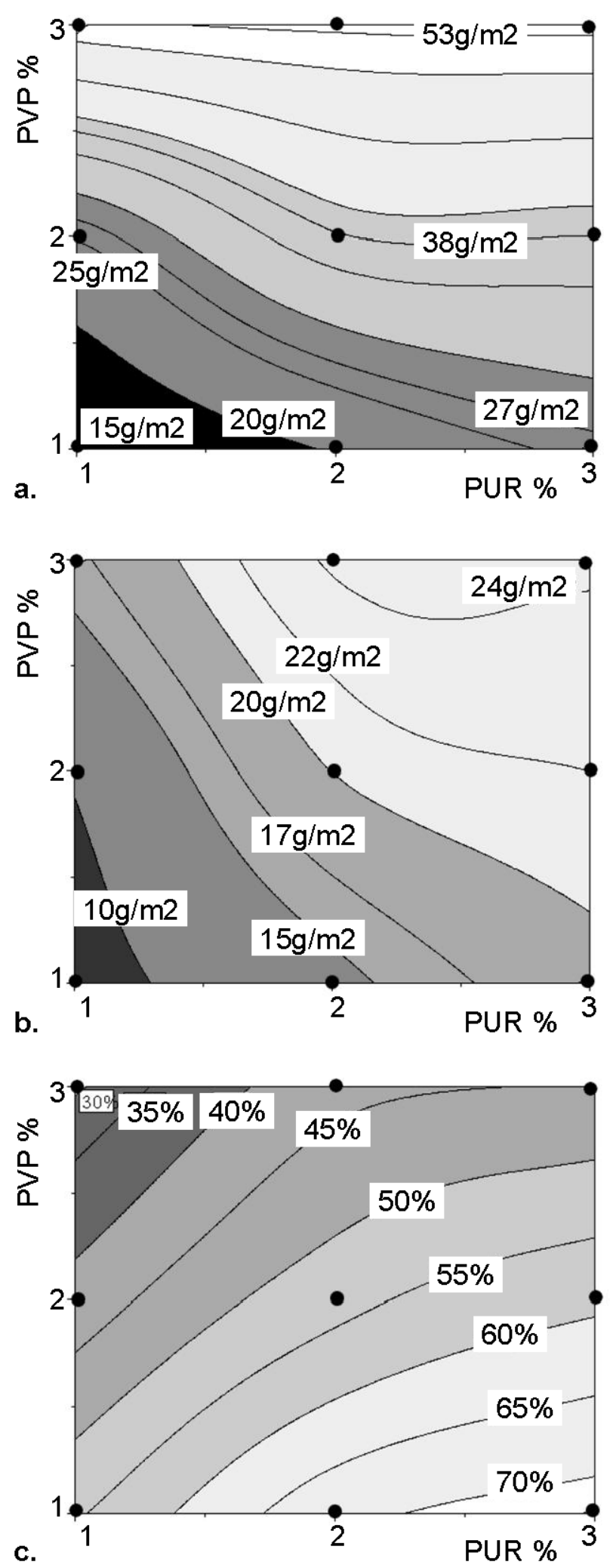

Figure 3. The influence of the polymer (PUR and PVP) concentration in coating solutions (system A) on the stability of the deposited coatings: dry mass of the deposited coating in $\mathrm{g}$ per $\mathrm{m}^{2}$ of substrate's surface before (a) and after washing out (b) and the resulted stability (c)

formance: predominantly the significant roughness of the modified surface. Polyurethane dissolving process occurred relatively much slower in comparison with PVP, and in addition its higher concentration does not bring the desirable effect - it does not improve the surface physical properties.
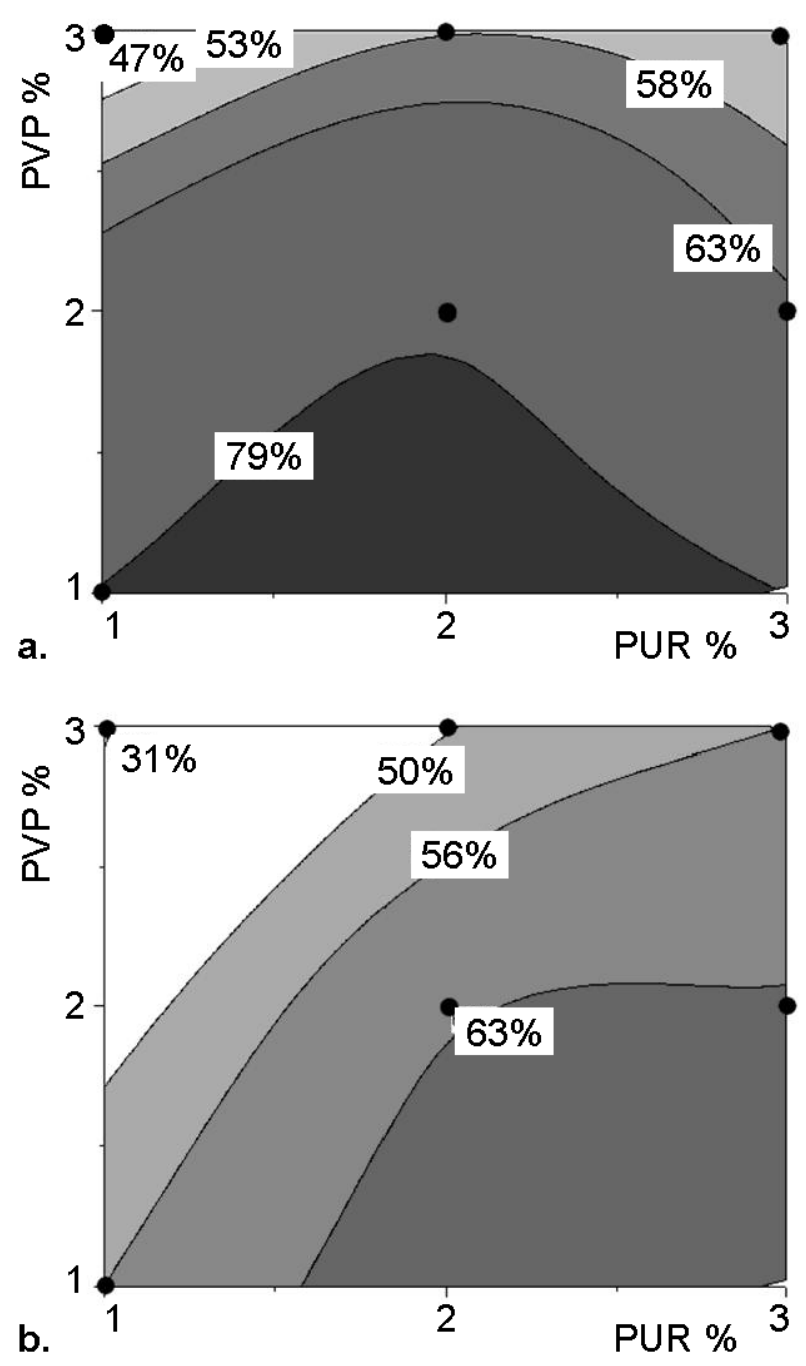

Figure 4. The influence of the polymer (PUR and PVP) concentration in coating solutions (system A) on the relative static (a) and kinetic (b) friction factors; friction factor of the uncoated sample is $100 \%$; dark points represent the composition of the tested samples

Another basic process parameter to consider is the length of solution storage time. It also depends on the solvent system used to prepare the solution. Comparing coating application carried out just after dissolving polymers $(0 \mathrm{~h})$ with this performed after $24 \mathrm{~h}$, the latter enables not only the higher mass of hydrogel deposited on the surface but also the formation of the more stable layer. The obtained values have been presented in Figures 5 a and $\mathrm{b}$.

The polymer chains may require a longer period of time in order to become completely expanded and to expose the side groups to contact with the surroundings, resulting the increase in amount of polymers binding to the surface when the device is immersed in 24-hours solutions.

Indeed, the observation of the coatings obtained from system A indicates that the longer solution storage time (up to three days) the more advantageous physical properties of formed coatings. The lowest values of both friction coefficients (static and kinetic) were recorded when the application of hydrogel layer was performed after three days of polymers dissolving in an appropriate system of solvents (A-72 in Figure 6). For system $G$ the opposite tendency has been observed (Figure 5), due to the lower 


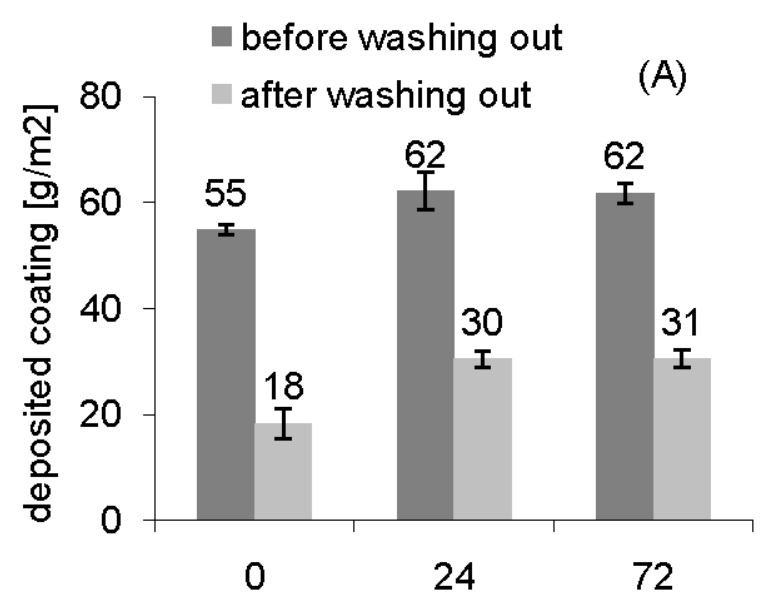

a. solution storage time [h]

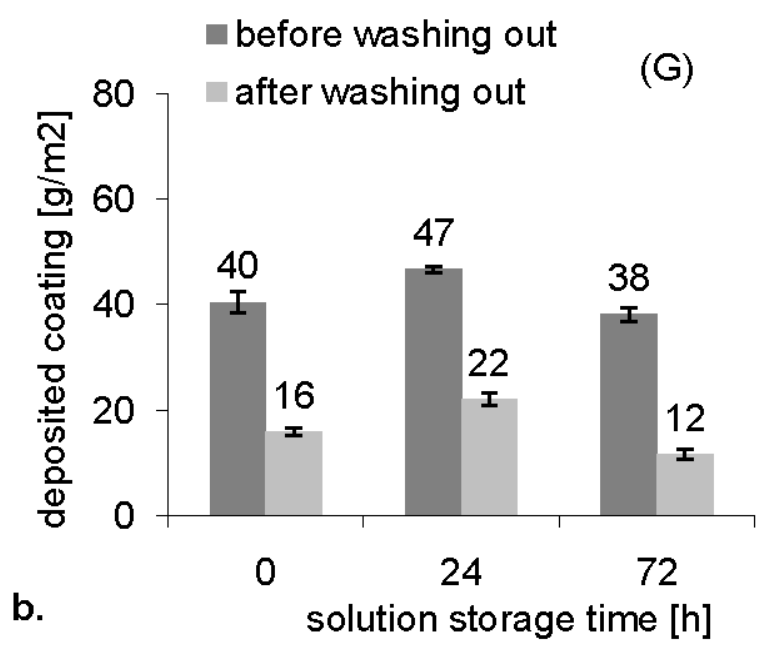

Figure 5. The influence of the coating solutions storage time on the mass of the deposited coatings; a. - solvent system A; b. - solvent system $G$

stability of its solutions. This could be related to the beginning of the intermolecular cross-linking formation. In the polymer solution whose concentration is higher than $1 \%(\mathrm{w} / \mathrm{v})$ the molecules are not isolated from each other and after some time, the interaction between them is essential enough to successfully prevent the side chains from interacting with the device surface during the coat- ing application process. Therefore the lower average mass of polymers was precipitated after $72 \mathrm{~h}$ of the solution storage.

When polymer solution had been heated up to 40 or $55^{\circ} \mathrm{C}$ the higher average mass of polymer was deposited on the surface of the modified device (Figure 7), but at the same time the obtained coatings were less durable in comparison with those formed by dipping in the solution of ambient temperatures (at least 2-times for $55^{\circ} \mathrm{C}$ in comparison with $22^{\circ} \mathrm{C}$ ).

The studies have also reported that the drying temperature does not influence the hydrogel layer durability. Maintaining the substrates just after coating application at the temperature about $50^{\circ} \mathrm{C}$ caused the decrease in the measured kinetic friction coefficients in comparison with those, whose hydrogel layers were dried in $32^{\circ} \mathrm{C}(7 \%$ for the coatings from system $\mathrm{G}$ and $18 \%$ from $\mathrm{A})$. Water uptake was lower for higher drying temperature $\left(67^{\circ} \mathrm{C}\right)$, which can be connected with the creation of more tight net structure of the gel. Application of elevated temperature is limited to about $55-65^{\circ} \mathrm{C}$ due to the thermal properties of the PVC backbone. To assure good modification process efficiency, determined by the average total mass of both adsorbed the polymers and the stability of

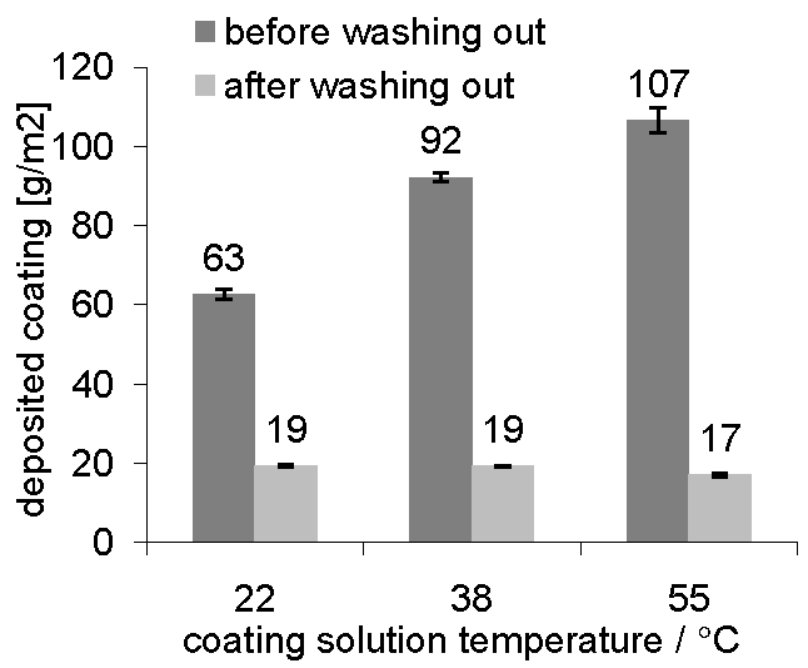

Figure 7. The influence of the coating solutions temperature on the mass of the deposited coating (system A)

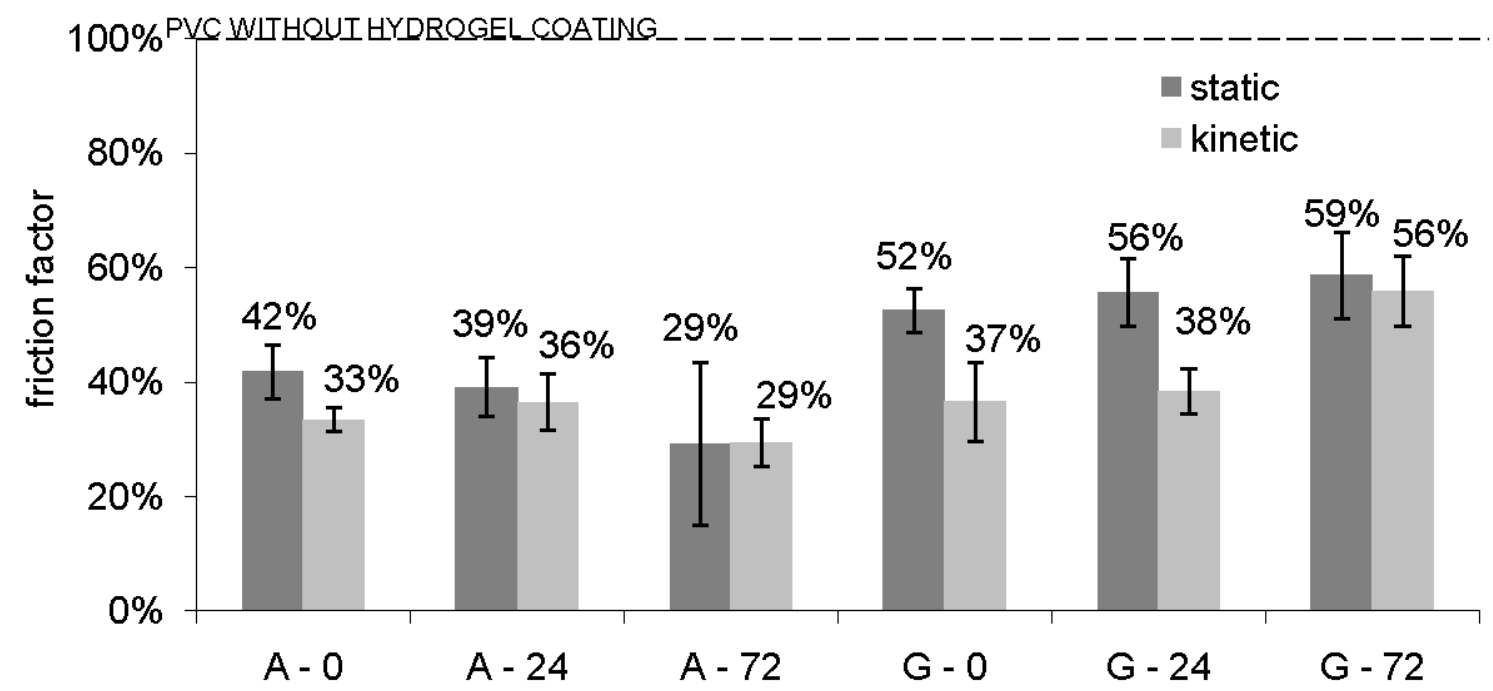

Figure 6. The influence of the coating solutions storage time $(0,24$ and $72 \mathrm{~h})$ on the friction factor; the value $100 \%$ represents the friction factor of the uncoated PVC 
the formed coatings, the length of break between the first and second process step should range from a dozen or so to 30 seconds when the system A is used. As one would expect this probably also depends on the solvents selected to prepare polymer solutions.

\section{FTIR-ATR spectra}

The existence of a durable hydrophilic layer on modified substrates was confirmed by FTIR-ATR spectroscopy. The IR spectra of hydrogel coated tubes and catheters revealed bands not visible in a pure substrate, but characteristic solely of PVP, PUR or PUR/PVP interpolymer spectra (Figure 8). The pyrrolidone ring in PVP contains a carbonyl moiety whose stretching band is observed at wave number about $1650-1655 \mathrm{~cm}^{-1}\left(1647 \mathrm{~cm}^{-1}\right.$ for thin film interpolymer). The spectrum of pure PVP displayed also the absorption band at the frequencies $1286 \mathrm{~cm}^{-1}$ characteristic for $\mathrm{N}-\mathrm{H}$ stretching band. The spectra of coated catheters and tubes exhibit these absorption peaks at $1288 \mathrm{i} 1289 \mathrm{~cm}^{-1}$, respectively. The hydrophilic character of the obtained coatings was confirmed by the presence of band in the range of $3400-3300 \mathrm{~cm}^{-1}$, attributed to the groups able to create hydrogen bonds and adsorbed water molecules.

In further examination the IR spectra of catheter surface and tube surface coated by dipping in the same system solutions (system A) were compared. They were nearly identical (Figure 9); the only noticeable differences con-

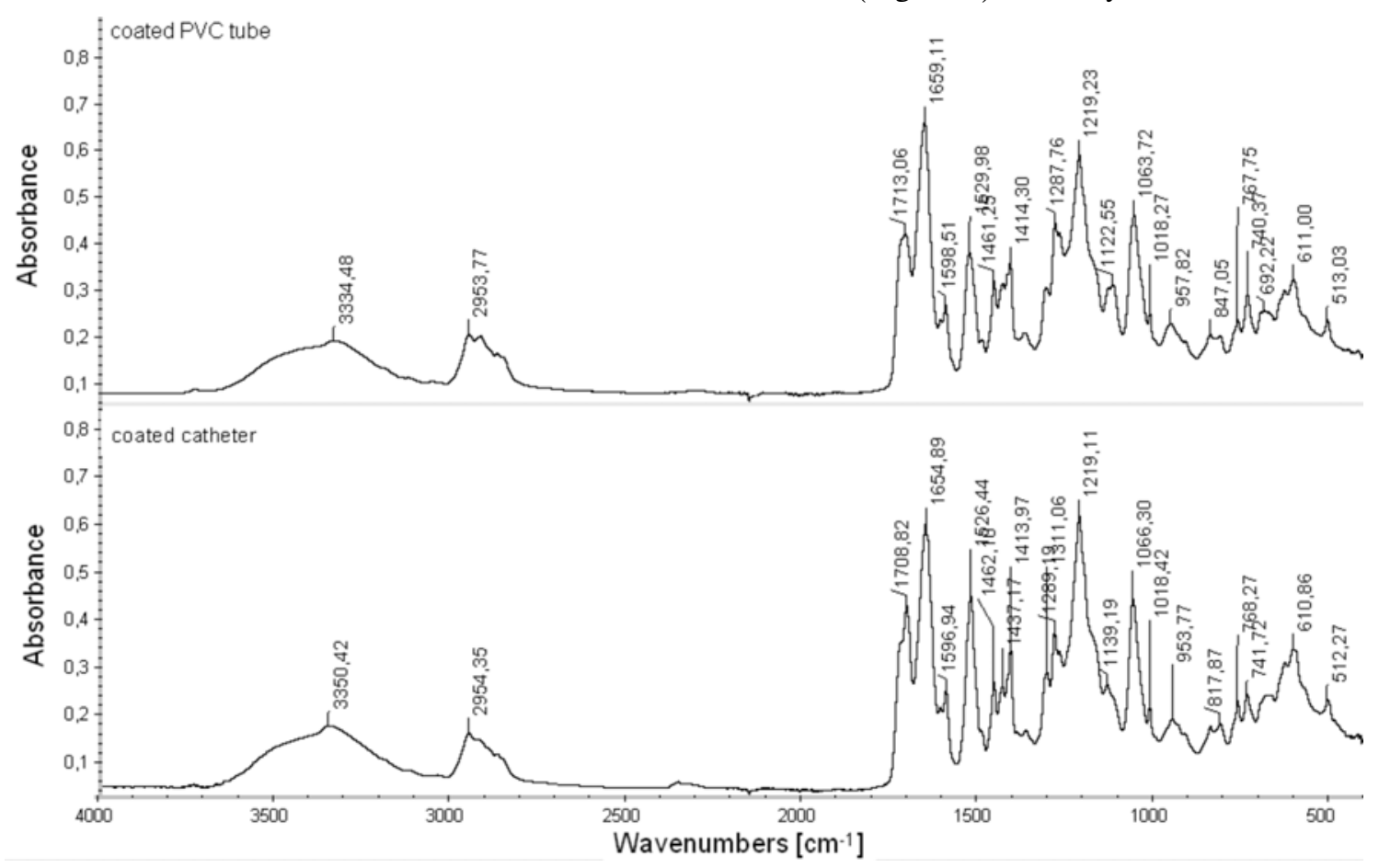

Figure 9. FTIR-ATR spectra of PUR/PVP hydrogel coated PVC tube and urological catheter; similar despite differences in PVC grade and plasticizers content

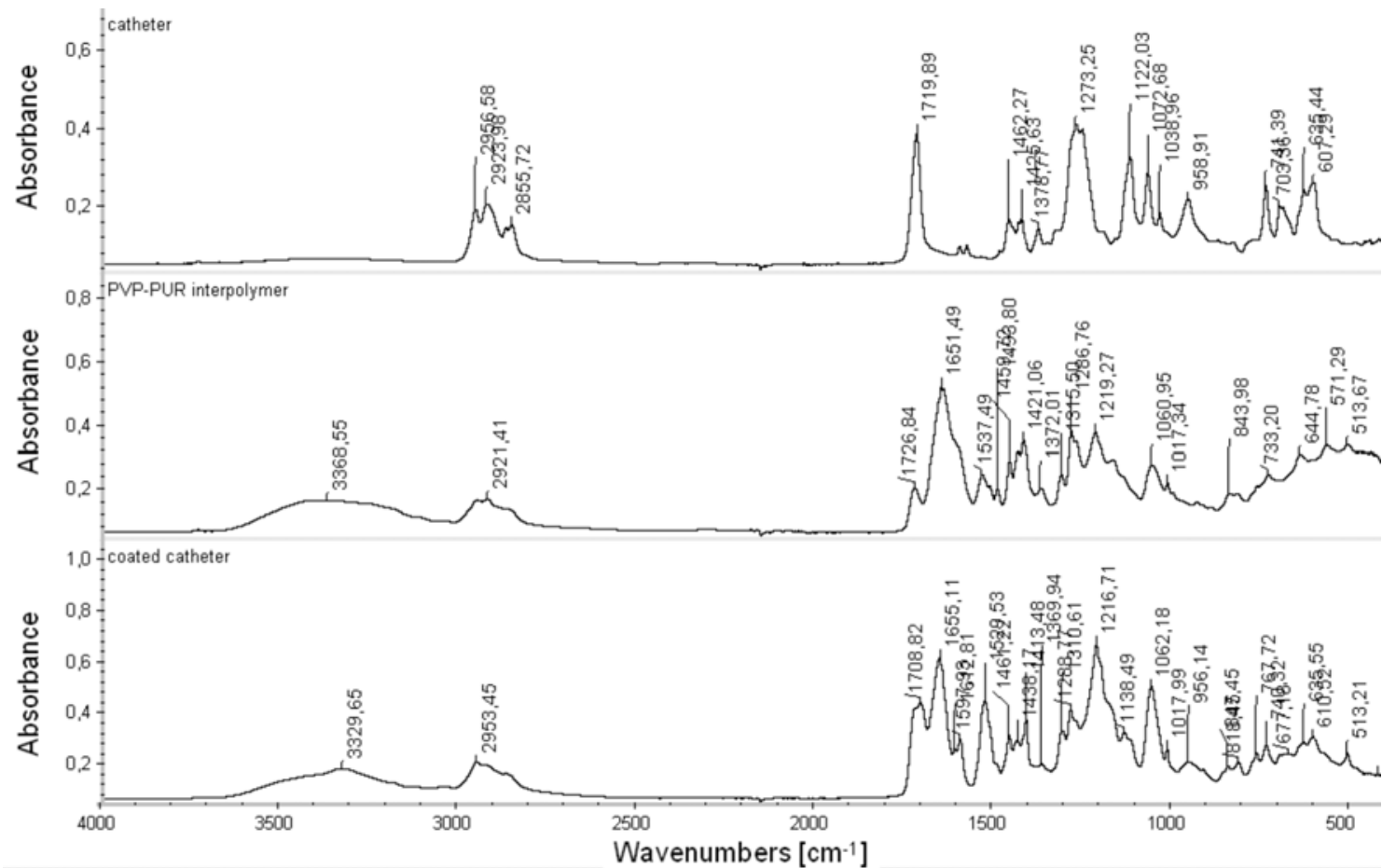

Figure 8. FTIR-ATR spectra of the unmodified PVC catheter, PUR/PVP hydrogel film and the hydrogel coated catheter surface 
cerned the insignificant shifts in the recorded frequencies. A two-steps dip-coating modification process, applied in this study, can successfully modify the surface properties of the devices made of both investigated PVC types.

\section{Swelling studies}

As biocompatibility apparently can be related to water content, it seems to be essential to characterize how much water the hydrogel imbibes in the swollen state ${ }^{8}$. The swelling degree of gel samples formed from system A and $\mathrm{G}$ was determined by two methods. An example of the swelling weight ratio (S, defined by the equation 2 ) trend as a function of the hydration time (method I) is shown in Figure 10. The raw results obtained according to the method II are presented in Figure 11.

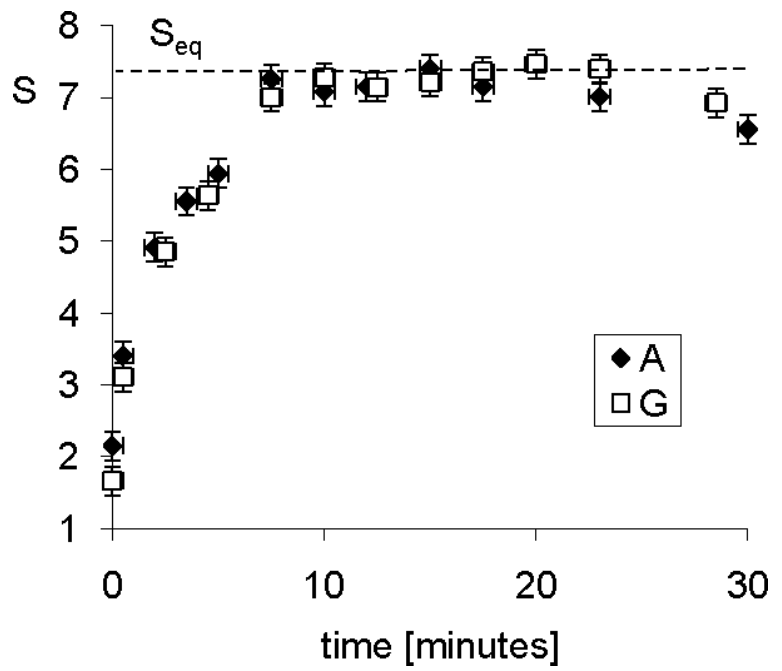

Figure 10. The swelling weight ratio, $\mathrm{S}$, calculated for thin $\mathrm{PVC} /$ PVP hydrogel films prepared from A and G systems of solvents according to the method I approach

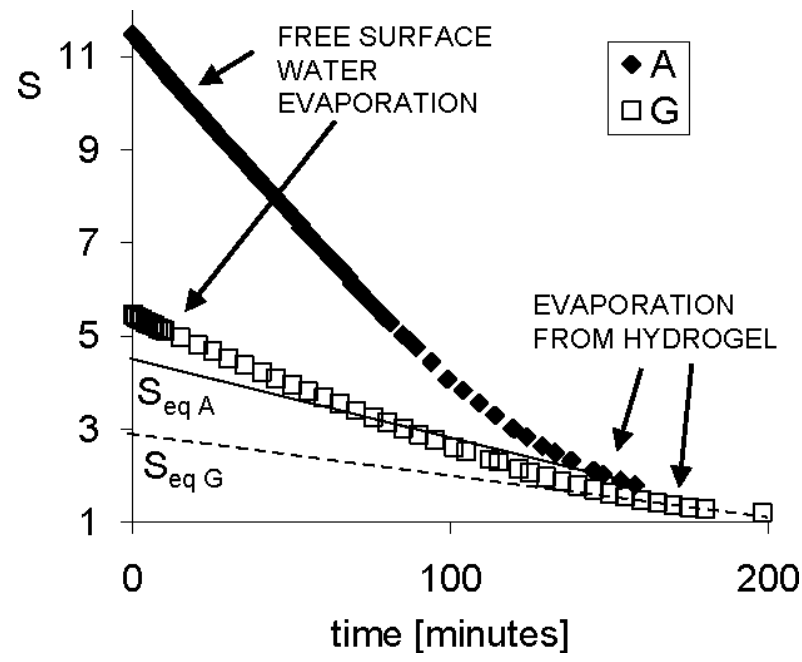

Figure 11. The swelling weight ratio, S, calculated for thin PVC/ PVP hydrogel films prepared from A and G systems of solvents, according to the method II approach

The results of the first approach (blot and weight method; method I) showed that there was no difference in the defined by Eq. 4 equilibrium water content $C_{w}$ (Figure 12) mean values between two tested types of hydrogel samples (solvent system A and G), whereas the results from the second technique (method II), indicated that the hydrogel formed from system A absorbs a higher amount

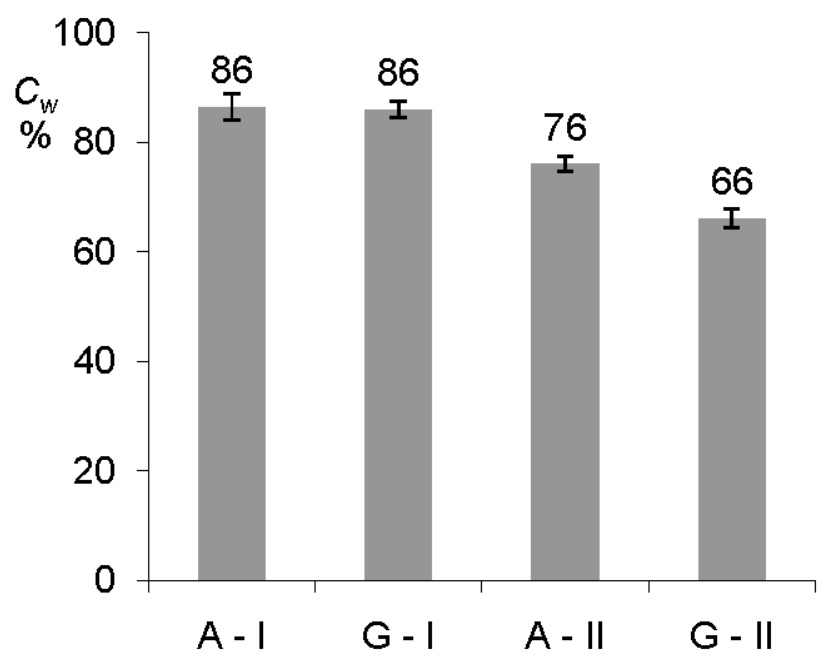

Figure 12. The equilibrium water content, $C_{w}$, calculated for thin PVC/PVP hydrogel films prepared from A and G solvent systems, according to the measurement methods I and II

of water in comparison with $\mathrm{G}$. In addition, the $C_{w}$ values obtained in method I were much higher than in method II.

The results of method I may have been influenced by the technique used to remove the excess of water from the tested samples. In the present studies it was realized by wiping in filter paper, which may lead to incomplete removal of water excess, or, on the contrary: overdrying and mechanical damage to the gel sample. This last effect may in part explain the unexpected decrease in the swelling weight ratio observed after 20 minutes of immersion in water. Highly hydrated, soft and thin polymer films are more prone to becoming damaged during manipulation required by method I. In addition tearing out some polymer chains from hydrogel network may also occur. Problems associated with the second method derive from the possibility of incorrect establishment of the moment in time considered to be boundary, when evaporation of the excessive water from the hydrogel surface ends, and starts from the hydrogel bulk.

The equilibrium water content $\mathrm{Cw}$ was found to be in the range of $66-86 \%$. According to the recorded results the hydrogels exhibit similarity of the fluid contents with those of living tissues. Thus, PVP/PUR interpolymer hydrogels could be used as biomaterial for biomedical applications.

\section{CONCLUSIONS}

Application of PUR/PVP hydrogel coating renders the PVC surface into more lubricious and resistant to wear friction, or washable with water, depending on the proper gel forming and curing conditions. In the present study the influence of several process parameters that seemed to be essential for dip-coating method efficiency was investigated.

The primary factors affecting the coatings quality are: the choice of solvents and the concentration of both polymers (PUR and PVP). Proper solvents have to fulfill not only the following requirements: high volatility, lack of the reactivity with substrates and other components of the solution, good wettability of the backbone, as these properties do not affirm the success of application process. 
Only three of the seven tested solution systems, allowed forming durable coatings, but not to the equal degree (e.g. system A and E). To achieve the lowest value of friction coefficient and the smoothest surface, 1\% PUR and 3\% PVP are suggested to be used in the case of the solvent system A, forming the most lubricious coating, whereas in the tested system G, giving slightly less slippery but more durable layers, the higher PUR concentration is recommended (about 2\% PUR and 3\% PVP).

The studies have also reported that the solution storage time is an important factor that significantly influences the properties of the hydrogel layer (preferably coating solutions should not be used within 24 hours after preparation).

Other parameters that should be controlled are: the length of break between the two steps of application technique and the temperatures of polymer solutions and in which the coatings are dried.

The amount of water that the PVP/PUR interpolymer can hold can be regulated due to several process parameters, like curing temperature and the system of solvents. This parameter is especially important in applications where hydrogels are used as wound dressings and drug delivery devices.

\section{Acknowledgements}

Presented work was supported by the research grant of Polish Ministry of Science and Higher Education.

The work of K. A. Kaźmierska was supported by the European Union in the framework of European Social Fund through the Warsaw University of Technology Development Programme.

\section{LITERATURE CITED}

1. Geever, L. M., Cooney, C. C., Lyons, J. G., Kennedy, J. E., Nugent, M. J. D., Devery, S. \& Higginbotham, C. L. (2008). Characterisation and controlled drug release from novel drug-loaded hydrogels. Eur. J. Pharm. Biopharm. 69(3), 1147 - 1159. DOI: 10.1016/j.ejpb.2007.12.021.

2. Peppas, N. A., Bures, P., Leobandung, W. \& Ichikawa, H. (2000). Hydrogels in pharmaceutical formulation. Eur. J. Pharm. Biopharm. 50(1), 27 - 46. DOI: 10.1016/S0939-6411(00)00090-4.

3. Swami, S. N. (2004). Radiation synthesis of polymeric hydrogels for swelling - controlled drug release studies. Doctoral dissertation, University of Western Sydney, School of Science, Food and Horticulture, New South Wales, Australia.

4. Gupta, P., Vermani, K. \& Garg, S. (2002). Hydrogels: from controlled release to $\mathrm{pH}$-responsive drug delivery. Drug Discov. Today 7(10), 569 - 579. DOI: 10.1016/S13596446(02)02255-9.

5. Karadag, E., Üzüm, Ö. B. \& Saraydin, D. (2005). Water uptake in chemically crosslinked poly(acrylamide-co-crotonic acid) hydrogels. Mater. Des. 26(4), 265 - 270. DOI: 10.1016/ j.materdes.2004.07.014.

6. Wichterle, O. \& Lim, D. (1960). Hydrophilic gels for biological use. Nature 185, 117 - 118. DOI: 10.1038/185117a0.

7. Lim, F. \& Sun, A. M. (1980). Microencapsulated islets as bioartificial endocrine pancreas. Science 210, 908 - 910. DOI: $10.1126 /$ science.6776628.

8. Gorman, S. P., Tunney, M. M., Keane, P. F., Van Bladel, K. \& Bley, B. (1998). Characterization and assessment of a novel poly(ethylene oxide)/polyurethane composite hydrogel (Aquavene) as a ureteral stent biomaterial. J. Biomed. Mater. Res. 39(4), 642 - 649. DOI: 10.1002/(SICI)10974636(19980315)39:4<642::AID-JBM20>3.0.CO;2-7.
9. Tunney, M. M. \& Gorman, S. P. (2002). Evaluation of a poly(vinyl pyrollidone)-coated biomaterial for urological use. Biomaterials 23(23), 4601 - 4608. DOI: 10.1016/S01429612(02)00206-5.

10. Yang, S. H., Lee, Y. S., Lin, F. H., Yang, J. M. \& Chen, K. S. (2007). Chitosan/poly(vinyl alcohol) blending hydrogel coating improves the surface characteristics of segmented polyurethane urethral catheters. J. Biomed. Mater. Res. B Appl. Biomater. 83(2), 304 - 313. DOI: 10.1002/jbm.b.30796

11. LaPorte, R.J. (1997). Hydrophilic polymer coatings for medical devices: structure/ properties, development, manufacture, and applications. Boca Raton, USA: CRC Press.

12. Micklus, M. J \& Ou-Yang, D. T. (1978). U.S. Patent No. 4,100,309. Washington, D.C.: U.S. Patent and Trademark Office.

13. Kaźmierska, K., Szwast, M. \& Ciach, T. (2008). Determination of urethral catheter surface lubricity. J. Mater. Sci. Mater. Med. 19(6), 2301 - 2306. DOI: 10.1007/s10856-0073339-4.

14. Kaźmierska, K. A., Kuc, K. \& Ciach, T. (2008). Polyvinylpyrrolidone-polyurethane interpolymer hydrogel coating as a local drug delivery system. Acta Pol. Pharm. 65(6), $763-$ 766. Retrieved January 28, 2010, from http://www.ptfarm.pl/ pub/File/acta_pol_2008/6_2008/763-766.pdf.

15. D'Errico, G., De Lèllis, M., Mangiapia, G., Tedeschi, A., Ortona, O., Fusco, S., Borzacchiello, A. \& Ambrosio, L. (2008). Structural and mechanical properties of UV-photocross-linked poly(N-vinyl-2-pyrrolidone) hydrogels. Biomacromolecules 9(1), 231 - 240. DOI: 10.1021/bm7008137. 